\title{
Personal health benefits of Masters athletics competition
}

\author{
R. J. Shephard MD PhD D.P.E. ${ }^{*+}$, T. Kavanagh MD*, D. J. Mertens MBBS MSc*, \\ S. Qureshi MSc* and M. Clark BSc* \\ *Toronto Rehabilitation Centre and ${ }^{\dagger}$ School of Physical and Health Education, University of Toronto, Toronto, \\ Canada
}

\begin{abstract}
Questionnaires (750 respondents, $44.4 \%$ response rate) examined the long-term health value of endurance exercise training in older age-classed competitors ('Masters Athletes', 551 men and 199 women) over a 7-year period (1985-1992). The majority had initially completed maximal exercise tests. The weekly time devoted to training, competition and exercise-related travel was 10 to $30 \mathrm{~h}$, and the annual expenditure on clothing, equipment and entrance fees was typically in the range Canadian \$500-1500. Despite their age (mean(s.d.) 58(10), current range $40-81$ years), only $1.4 \%$ reported sustaining a non-fatal heart attack and $0.6 \%$ had required bypass surgery over the 7-year interval. The majority $(90 \%)$ were very interested in good health; $76 \%$ considered themselves as less vulnerable to viral illnesses than their peers, and $68 \%$ regarded their quality of life as much better than that of their sedentary friends. The majority of former smokers had stopped smoking before they began training, but $37 \%$ indicated that exercise had helped them in smoking withdrawal. In keeping with their health-conscious attitude, $59 \%$ had regular medical check-ups, and $86 \%$ obeyed legislation requiring use of a seat-belt when driving. In contrast with many older people, $88 \%$ slept well or very well. Slightly over half of the sample $(57 \%)$ had sustained some injury which had limited their training for one or more weeks over the 7-year study. Although participation in Masters competition appears to carry considerable health benefits, gains may in part reflect an overall healthy lifestyle.
\end{abstract}

Keywords: cardiovascular health, cigarette smoking, health behaviour, immune function, injuries, lifestyle, Masters competition, quality of life

It is widely supposed that regular physical activity confers substantial health dividends on the middleaged adult. Support for this view has been derived from both meta-analyses ${ }^{1,2}$ and from several large individual prospective surveys ${ }^{3-6}$. Subjects have been classified initially, on the basis of a physical activity questionnaire ${ }^{3-5}$. or a treadmill tolerance time ${ }^{6}$, and subsequent questioning has evaluated cardiac morbidity or mortality patterns. Such studies have demonstrated that the more active members of

Address for correspondence: Professor Roy J. Shephard, School of Physical and Health Education, 320, Huron St., Toronto, Ontario M5S 1A1, Canada the population have a substantial reduction in the incidence of cardiac problems, of certain cancers, and of maturity-onset diabetes mellitus, with an imputed increase of lifespan for the more active members of the sample. However, the type and intensity of activity needed to realize such benefits has been less clearly defined. Morris et al. ${ }^{4}$ suggested that English civil servants needed a minimum leisure energy expenditure of $31.4 \mathrm{~kJ}(7.5 \mathrm{kcal})$ per minute in order to gain improved health. Paffenbarger et al. ${ }^{5}$ also noted an optimization of benefit at a weekly energy expenditure of $8.4 \mathrm{MJ}(2000 \mathrm{kcal})$; although they spoke of gains from activities such as climbing 50 stairs per day and walking a few city blocks, the 8.4 MJ total would imply five 1 -h sessions per week at a gross energy expenditure of about $33.5 \mathrm{~kJ} \mathrm{~min}^{-1}$ $\left(8 \mathrm{kcalmin}{ }^{-1}\right)$. Finally, Blair et $a .^{6}$ noted in their prospective studies of all-cause mortality that the greatest aerobic fitness-related benefit was seen at the lower end of the population distribution curve, in comparing those subjects who initially had a peak aerobic effort of seven rather than six times their resting metabolism.

There are substantial difficulties in making more than a general interpretation of these findings. Even when much time is given to both the design and the administration of physical activity questionnaires, the individual responses have only a limited reliability and validity ${ }^{7}$. Likewise, an individual's aerobic power is strongly influenced not only by habitual physical activity, but also by constitutional factors ${ }^{8}$. Further, the statistical power of community surveys is limited, particularly in North America, because only a small proportion of most samples shows even a moderate level of physical activity ${ }^{7,9}$.

The specific health advantages that could be derived from participation in various types of competitive sport relative to everyday activities such as walking and stair climbing remains unclear. Some of the calculations of Paffenbarger ${ }^{10}$ seem to suggest that for a given reported total leisure energy expenditure, vigorous sport confers somewhat greater health benefits than other forms of physical activity. In his most recent report, Morris ${ }^{4}$ also found much greater cardiac benefits from vigorous sport (an energy expenditure of more than $31.4 \mathrm{~kJ} \mathrm{~min}^{-1}$, $7.5 \mathrm{kcal} \mathrm{min}^{-1}$ ) than from more moderate activities. In 
contrast, Wannamethee and Shaper ${ }^{11}$ found that vigorous physical activity was less beneficial than more moderate pursuits. One immediate problem is the heterogeneous nature of 'sport'. Masters athletes are one group of middle-aged and older subjects who practice substantial and well-documented types and amounts of physical activity. We thus thought it worthwhile to conduct a 7-year prospective study on a sample of Masters competitors. The respondents (551 men and 199 women) were divided into endurance competitors and those engaged in activities with a strong social connotation. A detailed analysis of both morbidity and health behaviour was undertaken on these specific subgroups.

\section{Subjects and methods}

The volunteers were initially recruited at the Toronto Masters Games, in August of 1985. Details of their health, sociodemographic and physiological characteristics have been discussed previously ${ }^{12}, 13$. In the summer of 1992, a further questionnaire was circulated and replies were received from 750 of the 1689 subjects (a response rate of $44.4 \%$ ). The 750 respondents in the present study were all initially in good clinical health, although a substantial proportion had an exercise stress electrocardiogram (ECG) suggestive of silent myocardial ischaemia (for $16.2 \%$ of the men and $20.2 \%$ of the women the ECG showed an ST segmental depression of $2 \mathrm{~mm}$ or more during all-out exercise).

The current age range (1992) was from 40 to 81 years (mean(s.d.) $58(10)$ years). The age distribution at entry (1985) is shown in Table 1.

Subjects were arbitrarily divided into endurance competitors (participants in endurance running, orienteering, swimming, rowing and cycling, $61.2 \%$ of the men and $65.4 \%$ of the women) and participants in social, recreational sports such as the racquet sports $(38.8 \%$ of the men and $34.6 \%$ of the women). The training plans initially adopted by the endurance competitors have been described previously ${ }^{12,13}$. Although far removed from the very heavy endurance training programmes followed by some young athletes, nevertheless, the most common weekly time devoted to training, competition and related travel, as reported at the 7-year follow-up, was $6-10 \mathrm{~h}$. In terms of the criteria of Blair et al. ${ }^{6}$, the initial fitness level decreased from 14 metabolic equivalents (METS) in the men and 12.5 METS in the women of our youngest age group to 8.7 METS (men) and 7.7 METS (women) in the oldest age category.

\section{Physiological data}

Details of the test methods and the findings of the initial laboratory evaluation have already been published $^{12,13}$. In brief, peak aerobic power was determined directly by having subjects carry to exhaustion a progressive cycle ergometer test with continuous measurement of oxygen consumption. The electrocardiogram (ECG) was monitored throughout, using the CM5 lead configuration, and the maximum depression of the ST segment was recorded. Three skinfolds (triceps, subscapular and
Table 1. Age distribution of subjects at beginning of study (1985)

\begin{tabular}{|c|c|c|c|c|c|c|c|c|c|}
\hline \multicolumn{10}{|c|}{ Age (years) } \\
\hline \multicolumn{2}{|c|}{$<40$} & \multicolumn{2}{|c|}{$40-49$} & \multicolumn{2}{|c|}{$50-59$} & \multicolumn{2}{|c|}{$60-69$} & \multicolumn{2}{|c|}{$>70$} \\
\hline$M$ & $F$ & $M$ & $F$ & $M$ & $F$ & $M$ & $F$ & $M$ & $F$ \\
\hline 36 & 32 & 209 & 88 & 198 & 57 & 89 & 20 & 22 & 5 \\
\hline
\end{tabular}

suprailiac) were measured as proposed by the International Biological Programme ${ }^{14}$. The percentage of body fat was predicted using the corresponding three-fold equations of Durnin and Womersley ${ }^{15}$ and the density formula of Brozek et al. ${ }^{16}$.

\section{Questionnaire}

Data on lifestyle and subsequent health were obtained by the mailed questionnaire. Questions examined health status, injury experience and health behaviour over the 7-year period from 1985 to 1992.

In terms of health, subjects were asked specifically to indicate the onset of diabetes, physician-diagnosed hypertension, a non-fatal 'heart attack' and coronary by-pass surgery. They were also asked to rate their incidence of colds, coughs and 'flu' relative to sedentary subjects of the same age (using a threepoint scale), and (if there was a weekly training mileage at which they became chronically fatigued and susceptible to colds and ' $\mathrm{flu}^{\prime}$ '), to indicate this mileage. Finally, subjects were asked to rate their overall quality of life relative to their nonexercising peers of similar age on a five-point scale.

In terms of injuries, note was taken of all incidents causing a cessation of training for 1 week or more over the 7-year period. The number of incidents attributable to training and to competition was examined, and the type of activity causing the injury was noted. Subjects who developed a 'runner's high' were also questioned as to whether they thought this made them take risks with traffic.

In terms of health behaviour, subjects were asked to rate their interest in good health and the frequency of medical check-ups, both on three-point scales. The 223 respondents who had stopped smoking were also asked to indicate whether they had done this before or after beginning serious training, and to rate the perceived contribution of exercise to smoking cessation on a four-point scale. Average hours of sleep were reported, and the quality of sleep was rated on a four-point scale. Finally, subjects were asked whether they 'always' used a seat belt when driving.

\section{Results}

\section{General health}

Remarkably few respondents had developed a serious illness over the 7 years of observation. Ten subjects $(1.4 \%)$ had developed a non-fatal heart attack (six endurance men, $1.8 \%$, three recreational men, $1.4 \%$ one recreational woman, $1.5 \%$ ). The initial profile of this subgroup showed relatively little 
Health and Masters competition: R. J. Shephard et al.

unexpected information; four of the ten had undergone detailed physiological evaluation in 1985. Three of the four had been smokers, and three of the four had pushed themselves to a rating of perceived exertion (RPE) of 20 units during testing, the average maximal oxygen intake $\left(3.071 \mathrm{~min}^{-1}, 44.1 \mathrm{ml}\right.$ [kg.min $]^{-1}$ ) being relatively high for their average age of 55 years. Two of the four had shown significant ST depression on exercise electrocardiography ( 2.5 and $1.5 \mathrm{~mm}$, respectively). A total of ten incidents in 7 years is equivalent to approximately two non-fatal heart attacks per 1000 subjects per year. To this total may be added four subjects who received cardiac by-pass surgery, again a rate of about one per 1000 per year, for a total cardiac morbidity of three per 1000 per year. Unfortunately, the proportion of nonrespondents is too large to speculate about deaths, cardiac or noncardiac.

A total of 30 subjects $(4 \%)$ developed physiciandiagnosed hypertension over the 7 years (17 endurance men, $5.0 \%$; eight recreational men, $3.8 \%$; four endurance women, $3.0 \%$; one recreational woman, $1.5 \%$ ); in 19 of the 30 , this had been sufficient to require the prescription of specific hypotensive medication. The overall incidence of diagnosed hypertension was thus 5.5 cases per 1000 per year. The subjects in this category were initially a little older than the overall sample (men 58.9 years; women 61.8 years). Predictions of body fat content must be interpreted cautiously, since the number of subjects of comparable age used in establishing the prediction equations was relatively small. However, it appears that the Masters competitors carried a fair amount of fat relative to younger endurance athletes (average $19.6 \%$ in men and $27.9 \%$ in women, excess mass relative to actuarial tables, $9.8 \mathrm{~kg}$ men, $6.6 \mathrm{~kg}$ women), and their blood pressures at entry were already borderline (resting, $151 / 92 \mathrm{mmHg}$, men; $148 / 90 \mathrm{mmHg}$, women; peak exercise $240 / 94 \mathrm{mmHg}$, men; $217 / 70 \mathrm{mmHg}$, women). Four of the men and one of the women showed exercise-induced ST depression, the deepest being $2.5 \mathrm{~mm}$. Four men and one woman were former smokers.

Five cases of maturity-onset diabetes mellitus were diagnosed over the 7 years, four in male endurance participants, and one in a female endurance athlete, for an average incidence of 0.4 cases per 1000 per year. This subgroup were no fatter than those developing hypertension (average body fat $18.6 \%$ for men, $26.5 \%$ for women).

The majority of subjects $(76 \%)$ considered themselves as less vulnerable to colds, coughs and 'flu' than their sedentary colleagues (Table 2). Only

Table 2. Influence of sport upon vulnerability to acute infections, relative to age matched peers

\begin{tabular}{|c|c|c|c|c|c|c|}
\hline \multirow[t]{2}{*}{ Type (\%) } & \multicolumn{2}{|c|}{$\begin{array}{c}\text { Less } \\
\text { vulnerable }\end{array}$} & \multicolumn{2}{|c|}{ Same } & \multicolumn{2}{|c|}{$\begin{array}{c}\text { More } \\
\text { vulnerable }\end{array}$} \\
\hline & $M$ & $F$ & $M$ & $F$ & $M$ & $F$ \\
\hline Endurance & 76.7 & 77.0 & 22.1 & 18.3 & 1.3 & 4.8 \\
\hline Recreational & 76.0 & 70.0 & 23.6 & 30.0 & 0.5 & 0.0 \\
\hline
\end{tabular}

Table 3. Relative quality of life ratings

\begin{tabular}{lccccccccc}
\hline Type (\%) & \multicolumn{4}{c}{ Men } & \multicolumn{4}{c}{ Women } \\
& 2 & 3 & 4 & 5 & 1 & 2 & 3 & 4 & 5 \\
\hline Endurance & 0.3 & 3.7 & 28.6 & 67.4 & 1.6 & 1.6 & 3.9 & 20.9 & 72.0 \\
Recreational & - & 6.7 & 30.5 & 62.8 & 1.6 & 1.6 & 3.2 & 29.7 & 73.9 \\
\hline
\end{tabular}

$1.5 \%$ overall thought themselves to be more vulnerable than their peers. Nevertheless, the small number of vulnerable individuals was concentrated among the endurance participants. Some $16 \%$ of the overall group were conscious of a running or jogging mileage at which they became chronically fatigued and developed an enhanced susceptibility to acute infections (in endurance sports, $16.0 \%$ of the men, $14.2 \%$ of the women; in recreational sports $9.4 \%$ of the men, $13.8 \%$ of the women). The regularly tolerated weekly distance for vulnerable individuals varied with the type of training, the mode being 35 miles per week for jogging, 150 miles per week for cycling and 8.5 miles per week for swimming; problems were detected at respective modes of 45,190 and 10 miles per week.

The Masters athletes generally rated their overall quality of life as much higher than that of their sedentary peers (Table 3 ). Moreover, the proportion of subjects reporting the highest rating tended to increase rather than to decrease in those over the age of 60 years $(77.5 \%$ of elderly men, $74.6 \%$ of elderly women).

\section{Injuries}

Some $56.7 \%$ of the sample had incurred at least one injury interrupting training for more than a week during the 7-year period; $23.6 \%$ of the group had been injured during training, and $18.8 \%$ during actual competition. There was a similar incidence of injuries in endurance competitors $(60.1 \%$ of men, $50.7 \%$ of women) and in those engaged in recreational sports (54.9\% of men, $49.2 \%$ of women). The type of pursuit causing injury was identified by 212 individuals: $37.2 \%$ of lesions were associated with endurance running, $19.3 \%$ with swimming, $17.0 \%$ with cycling, $16.5 \%$ with team sports, $2.3 \%$ with weight-lifting, and $7.7 \%$ with other types of activity.

The majority of injuries were located in the lower limb $(34.2 \%)$ and knee $(22.2 \%)$. Other sites included the upper limb $(26.5 \%)$, the back $(13.8 \%)$ and hernias $(3.4 \%)$.

Some $41.7 \%$ of respondents said they had experienced a 'runner's high'. However, only $11.2 \%$ of these individuals thought that the euphoria was sufficient to cause them to take risks with traffic.

\section{Health behaviour}

The majority of the athletes indicated that they were interested in good health, the respective ratings being: very much $(90.9 \%)$; somewhat $(8.1 \%)$; and very little $(1.0 \%)$. In the men, a lack of interest in good health was concentrated among the recreational 
athletes, but the women showed little differentiation by type of sport (Table 4). Women had somewhat greater physician contact then the men, but the proportion of subjects making regular contact was similar for endurance and recreational sports.

Only $2.9 \%$ of subjects were still smoking, but a further $32.8 \%$ of the Masters competitors were former smokers. The proportion of continuing smokers was quite low, but tended to be greater among those involved in social, recreational sports (Table 6). The majority of athletes (191 of $223(85.7 \%)$ ) had stopped smoking before they began serious training. However, a number of participants in both endurance and recreational sports suggested that their involvement in Masters competition had helped the process of smoking withdrawal (Table 7).

The great majority of the subjects $(86 \%)$ indicated that they 'always' used a seat belt when driving, as is

Table 4. Health behaviour ratings

\begin{tabular}{|c|c|c|c|c|c|c|}
\hline \multirow[t]{3}{*}{ Type (\%) } & \multicolumn{6}{|c|}{ Level of interest in health } \\
\hline & \multicolumn{2}{|c|}{ Very much } & \multicolumn{2}{|c|}{ Somewhat } & \multicolumn{2}{|c|}{ Very little } \\
\hline & $M$ & $F$ & $M$ & $F$ & $M$ & $F$ \\
\hline Endurance & 91.1 & 90.7 & 7.4 & 6.2 & 1.5 & 3.1 \\
\hline Recreational & 85.3 & 93.8 & 11.4 & 6.2 & 3.3 & 0.0 \\
\hline
\end{tabular}

Table 5. Degree of contact with physician

\begin{tabular}{|c|c|c|c|c|c|c|}
\hline \multirow[t]{2}{*}{ Type (\%) } & \multicolumn{2}{|c|}{ None } & \multicolumn{2}{|c|}{ Some } & \multicolumn{2}{|c|}{ Regular } \\
\hline & $M$ & $F$ & $M$ & $F$ & $M$ & $F$ \\
\hline Endurance & 11.4 & 6.0 & 33.7 & 27.1 & 54.9 & 66.9 \\
\hline Recreational & 7.2 & 4.7 & 38.7 & 31.2 & 54.1 & 64.1 \\
\hline
\end{tabular}

legally required in Ontario; nonusers tended to be more frequent among social $(15.7 \%)$ than among endurance $(9.5 \%)$ competitors.

In contrast with the problems of sleeping reported by many sedentary older people, most of the Masters athletes $(88 \%)$ indicated that they slept well or very well (Table 8).

\section{Financial investment in participation}

Many of the subjects were investing substantial amounts not only of their time, but also of their disposable income in Masters competition each year (Table 9). The average reported sums, measured in actual expenditures of 1991 Canadian dollars, were for the endurance participants $\$ 1380$ (men) and $\$ 1472$ (women), and for the recreational participants $\$ 1778$ (men) and \$1466 (women).

\section{Discussion}

\section{General health}

The majority of the Masters athletes were undertaking substantially more physical activity then the general populations studied and discussed by epidemiologists. They also appeared to enjoy a substantial advantage of health relative to the general population, although there remains some potential for reporting bias, since conclusions are inevitably based upon the $44.5 \%$ of subjects who returned questionnaires.

In terms of the general quality of living, the $67 \%$ of endurance competitors who rated their status as much better than that of their peers may be compared with the Canada Health Promotion Survey $(1988)^{17}$, where only $55 \%$ of respondents aged $45-64$ years rated their health as either excellent or very good.

The incidence of cardiovascular disease may be compared with the recent figures of the Heart and Stroke Foundation of Canada ${ }^{18}$ - for the age decade

Table 6. The influence of endurance and recreational sport upon cigarette smoking and smoking withdrawal

\begin{tabular}{|c|c|c|c|c|c|}
\hline \multirow[t]{3}{*}{ Type of sport (\%) } & \multicolumn{5}{|c|}{ Smoking pattern } \\
\hline & Never & Stopped before & Stopped after & \multicolumn{2}{|c|}{ Still Smoke } \\
\hline & $M \quad F$ & $M \quad F$ & $M \quad F$ & & $F$ \\
\hline Endurance & 60.6 & 24.8 & 4.7 & 2.2 & 0.0 \\
\hline Recreational & 66.8 & 25.5 & 2.9 & 4.8 & 7.8 \\
\hline
\end{tabular}

Table 7. Perceived contribution of sport participation to process of smoking withdrawal

\begin{tabular}{|c|c|c|c|c|c|c|}
\hline \multirow[t]{3}{*}{ Type of sport (\%) } & \multicolumn{6}{|c|}{ Help in smoking cessation } \\
\hline & None & Some & \multicolumn{2}{|c|}{ Yes } & \multicolumn{2}{|c|}{ Very much } \\
\hline & $M \quad F$ & $M \quad F$ & $M$ & $F$ & $M$ & $F$ \\
\hline Endurance & 44.4 & 11.9 & 30.2 & 22.2 & 13.5 & 13.9 \\
\hline Recreational & $61.0 \quad 60.0$ & $\begin{array}{ll}9.1 & 10.0\end{array}$ & 20.8 & 30.0 & 9.1 & \\
\hline All & 53.4 & 9.2 & \multicolumn{2}{|c|}{26.6} & \multicolumn{2}{|c|}{11.1} \\
\hline
\end{tabular}


Table 8. Influence of gender and type of sport upon sleep patterns

\begin{tabular}{|c|c|c|c|c|c|c|}
\hline \multirow[t]{3}{*}{ Type of sport (\%) } & \multicolumn{6}{|c|}{ Sleep quality } \\
\hline & \multicolumn{2}{|c|}{$\begin{array}{c}\text { Very } \\
\text { soundly }\end{array}$} & \multicolumn{2}{|c|}{$\begin{array}{c}\text { Sleeping } \\
\text { well }\end{array}$} & \multicolumn{2}{|c|}{ Poor } \\
\hline & $M$ & $F$ & $M$ & $F$ & $M$ & $F$ \\
\hline Endurance & 25.7 & 37.6 & 62.7 & 50.4 & 11.6 & 12.1 \\
\hline Recreational & 22.4 & 17.2 & 62.6 & 70.3 & 15.0 & 12.5 \\
\hline All & \multicolumn{2}{|c|}{25.5} & \multicolumn{2}{|c|}{62.5} & \multicolumn{2}{|c|}{12.0} \\
\hline
\end{tabular}

Table 9. Financial investment of Masters athletes in clothing, equipment, fees and travel for competition

\begin{tabular}{lrrrrr}
\hline Type of sport & \multicolumn{5}{c}{ Annual investment (Canadian \$ per year) } \\
& $0-99$ & $100-299$ & $300-499$ & $500-999$ & $\geqslant 1000$ \\
\hline Men (\%) & & & & & \\
Endurance & 2.9 & 13.8 & 10.9 & 20.6 & 51.8 \\
$\begin{array}{l}\text { Recreational } \\
\text { Women (\%) }\end{array}$ & 0.5 & 9.0 & 6.9 & 23.8 & 59.8 \\
Endurance & 1.9 & 17.5 & 12.6 & 20.4 & 47.6 \\
Recreational & 4.3 & 8.7 & 6.5 & 19.6 & 60.9 \\
\hline
\end{tabular}

55-64 years, the mortality alone from ischaemic heart disease was 4.0 per 1000 per year in men and 1.1 per 1000 per year in women. Accepting the data at their face value, it would thus seem that there may be additional advantages in terms of both the quality of life and cardiac health when exercise is pursued beyond the minimum level currently recommended by epidemiologists.

A number of recent studies has focused upon the disadvantages of prolonged endurance exercise, particularly a potential suppression of immune function, with a resulting increase in the risk of acute infections ${ }^{19,20}$. A substantial proportion of the present sample of Masters competitors seemed aware of this phenomenon, but the great majority were currently achieving benefits to life quality and cardiovascular health at a somewhat lower and well-tolerated level of conditioning, where there was no evidence of an increased susceptibility to infection.

\section{Injuries}

Physical injuries were plainly a potential disadvantage of the vigorous training regimen for many of the group, although our definition of injury was a conservative one (interruption of training for 1 week). We did not solicit further details of severity in the present survey, but our earlier experience ${ }^{21}$ suggests that about a third of those who were injured (that is, about $19 \%$ of all subjects) would need to cease training for a month or more. Given the substantial gains in other areas of health, most competitors would probably agree that such a risk was acceptable.

A recent article pointed to a possible link between the 'runner's high' and the involvement of joggers in traffic accidents ${ }^{22}$. It is thus interesting that $11.3 \%$ of those exercising to the intensity of a 'high' admitted that they did develop feelings of 'invincibility'23, and were inclined to take risks with traffic in consequence.

\section{Lifestyle}

Part of the favourable health experience of the exerciser could reflect not a direct effect of physical activity, but rather an indirect impact of physical activity upon overall lifestyle, or even a common association between the practice of regular exercise and other positive health habits ${ }^{24}$.

This possibility has been discussed most frequently in the context of smoking withdrawal. Morgan et al..$^{25}$ noted that an unusually high proportion of Masters competitors had been successful in smoking withdrawal, and the authors of the report attributed this favourable outcome to involvement in Masters competition. In a more recent survey of this same population ${ }^{12,13}$, subject responses suggested that the majority of those who had been successful in smoking withdrawal had actually stopped smoking before they began serious training. The present findings support the latter view. Nevertheless, they also show that in a minority of former smokers, involvement in sport (particularly endurance competition) made a major contribution to the withdrawal process.

The distinction between endurance and social, recreational sport seems important from the viewpoint of health behaviour. The present findings support earlier association ${ }^{26}$, which suggested that despite a lack of communality between overall sports participation and other positive health behaviours, an association became apparent when participation in endurance sport was distinguished from the more social forms of physical activity. Specifically, in the present sample, more recreational than endurance athletes were still smoking. Moreover, more of the endurance than of the recreational athletes had stopped smoking after they became involved in sport, and almost three times as many of the ena . rance competitors found sport was helpful in smoking withdrawal. Such findings need verification on a larger sample, but they certainly support suggestions that those who are interested in promotion of a healthy overall lifestyle should commend endurance rather than social types of sport.

In conclusion, Masters athletes are inevitably a self-selected group, and in the present instance comparisons with the health experience of the general population are further constrained by the $45 \%$ response rate. Nevertheless, preparation for and participation in Masters competition was apparently associated with favourable prospects in terms of quality of life and the incidence of new cases of ischaemic heart disease, hypertension and diabetes, at least in our respondents. The activity levels adopted by competitors are substantially higher than in some recent public health recommendations ${ }^{6}$, and the question thus arises how far the favourable health experience is attributable to the high levels of physical conditioning. It would appear that older subjects can sustain such levels of activity without a negative influence upon their resistence to infectious 
disease. There is some threat of physical injury with intensive endurance training, but a $50 \%$ likelihood of stopping training for 1 week in 7 years seems an acceptable risk from an active lifestyle. Smoking cessation seems to be somewhat more frequently associated with endurance than with social, recreational types of sport, and at least a minority of endurance competitors perceive that involvement in competition was helpful to the withdrawal process.

\section{References}

1 Powell KS, Thompson PD, Caspersen CJ et al. Physical activity and the incidence of coronary heart disease. Ann Rev Publ Hlth 1987; 8: 253-87.

2 Berlin JA, Colditz GA. A meta-analysis of physical activity in the prevention of coronary heart disease. Am J Epidemiol 132: 1990; 612-28.

3 Morris JN, Everitt MG, Pollard R et al. Vigorous exercise in leisure time: protection against coronary heart disease. Lancet 1980; ii: $1207-10$.

4 Morris JN, Clayton DG, Everitt MG et al. Exercise in leisure time: coronary attack and death rate. Br Heart J 1990; 63: 325-34.

5 Paffenbarger RS, Hyde RT, Wing AL et al. Some interrelationships of physical activity, physiological fitness, health and longevity. In: C Bouchard, RJ Shephard, T Stephens, eds. Physical Activity, Fitness and Health. Champaign, Illinois, USA: Human Kinetics, 1993: 119-33.

6 Blair SN, Kohl HW, Paffenbarger RS, Clark DG, Cooper KH, Gibbons LW. Physical fitness and all-cause mortality. A prospective study of healthy men and women. JAMA 1989; 262: 2395-401.

7 Shephard RJ. Fitness of a Nation. Basel, Switzerland: Karger Publications, 1986

8 Bouchard C. Genetic determinants of endurance performance. In: RJ Shephard, PO Åstrand, eds. Endurance in Sport. Oxford, UK: Blackwell Scientific Publications, 1992: 149-62.

9 Montoye HJ. Physical Activity and Health: an Epidemiologic Study of an Entire Community. Englewood Cliffs, New Jersey, USA: Prentice Hall, 1975.

10 Paffenbarger RS. Contributions of epidemiology to exercise science and cardiovascular health. Med Sci Sports Exerc 1988; 20: 426-38.

11 Wannamethee G, Shaper AG. Physical activity and stroke in British middle-aged men. BMJ 1992; 304: 597-601.

12 Kavanagh T, Lindley LJ, Shephard RJ, Campbell R. Health and sociodemographic characteristics of the Masters competitor. Ann Sport Med 1988; 4: 55-64.

13 Kavanagh T, Mertens DJ, Matosevic V, Shephard RJ, Evans B. Health and aging of Masters athletes. Clin Sports Med 1988; 1: 72-88.

14 Weiner JS, Lourie JA. Practical Human Biology. London, UK: Academic Press, 1981.

15 Durnin JVGA, Womersley JA. Body fat assessed from total body density and its estimation from skinfold thickness: measurements on 481 men and women from 16 to 72 years. $\mathrm{Br}$ J Nutr 1974; 32: 77-97.

16 Brozec J, Grande F, Anderson JT Keys A. Densitometric analyses of body composition: revision of some quantitative assumptions. Ann NY Acad Sci 1963; 110: 492-502.

17 Health and Welfare Canada. Canada's Health Promotion Survey. Technical Report. Ottawa, Canada: Health and Welfare Canada, 1988.

18 Heart and Stroke Foundation of Canada. Cardiovascular Disease in Canada. Ottawa, Canada: Heart and Stroke Foundation of Canada, 1991.

19 Heath GW, Macera CA, Nieman DC. Exercise and upper respiratory tract infections: is there a relationship? Sports Med 1992; 14: 353-65.

20 Brenner I, Shek PN, Shephard RJ. Acute infections and exercise. Sports Med. 1993.

21 Kavanagh TK, Shephard RJ. The effects of continued training on the aging process. Ann NY Acad Sci 1977; 301: 656-70.

22 Shephard RJ. Vehicle injuries to joggers. Case report and review. J Sports Med Phys Fitness 1992; 32: 321-31.

23 Kostrubala T. Running: the grand illusion. In: Sachs $M H$, Sachs ML, eds. The Psychology of Running. Champaign, Illinois, USA: Human Kinetics, 1981.

24 Shephard RJ. Exercise and lifestyle change. Br J Sports Med 1989; 23: 11-21.

25 Morgan P, Gildiner M, Wright GR. Smoking reduction in adults who take up exercise: a survey of a running club for adults. Canadian Association for Health, Physical Education and Recreation Journal 1976; 42(5): 39-43.

26 Perrier/Great Waters of France. The Perrier Study: Fitness in America. New York, USA: Perrier/Great Waters of France, 1979. 